\title{
Caesarean scar ectopic pregnancy: imaging findings of this rare but potentially life- threatening condition
}

\author{
Joseph Andrew WK Tang *, Esther MF Wong, Wendy Shu
}

\begin{tabular}{l} 
Hong Kong Med J 2018;24:636.e1-2 \\
\hline DOI: 10.12809/hkmj176953
\end{tabular}

Caesarean scar ectopic pregnancy is a rare pregnancy complication with an estimated incidence of $1 / 1800$ to $1 / 2500$ pregnancies. ${ }^{1,2}$ Complications include uterine rupture, massive haemorrhage, placenta accrete, and pregnancy loss. ${ }^{3}$ Ultrasound examination is usually the first-line investigation. Magnetic resonance imaging (MRI) serves as a powerful confirmation tool. With its inherent superior tissue contrast and mulitplanar capability, MRI depicts anatomical details with robust reproducibility. ${ }^{4}$ Caesarean scar ectopic pregnancy is associated with a high risk of uterine rupture and uncontrollable haemorrhage. Expectant management is possible but not advocated. Surgical treatment leads to quicker postoperative recovery but may be associated with major haemorrhage. ${ }^{5}$ Other treatment includes systemic methotrexate and uterine artery embolisation. ${ }^{3}$

A high index of suspicion is required to diagnose this condition so that timely treatment can be initiated and life-threatening complications from a ruptured ectopic pregnancy prevented.

\section{Case}

A 34-year-old woman with a history of Caesarean section presented to the emergency department with per vaginal bleeding. Her pregnancy was 7 weeks of gestation by date.

On vaginal examination, the cervical os was closed and mildly blood-stained. She was haemodynamically stable with a normal haemoglobin of $12.9 \mathrm{~g} / \mathrm{dL}$ and beta-human chorionic gonadotropin $15877 \mathrm{mIU} / \mathrm{mL}$. Transvaginal ultrasound revealed a single intrauterine gestational sac in the lower segment of the uterus, closely related to the myometrium (Fig 1). The fetal pole with positive fetal heart beat was identified. Crown to rump length was $11 \mathrm{~mm}$, corresponding with 7 weeks and 1 day of gestation. The anterior uterine wall adjacent to the gestational sac was very thin with a thickness of only $4 \mathrm{~mm}$ (Fig 2). However, it was uncertain whether the placenta was directly implanted onto the Caesarean scar. A provisional diagnosis was made of pending abortion or Caesarean scar ectopic pregnancy. Magnetic resonance imaging of the pelvis was performed to determine whether the thin layer of soft tissue at the anterior uterine wall represented myometrium in the Caesarean scar with placental implantation elsewhere or if the placental tissue was

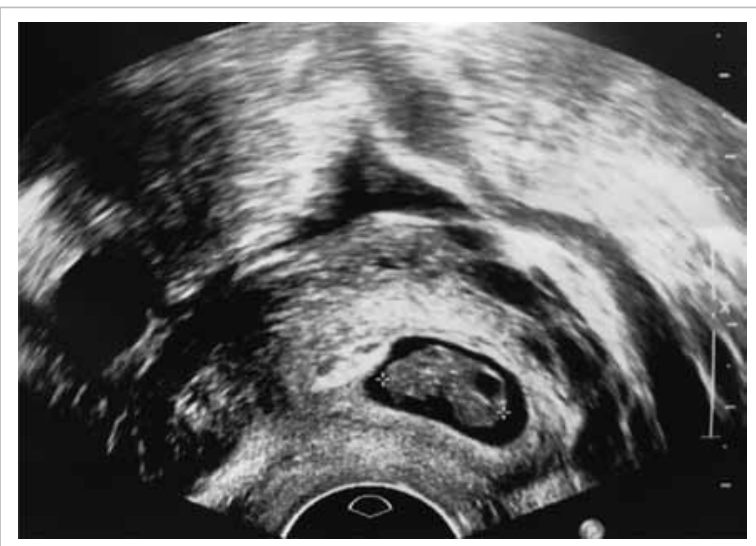

FIG I. Transvaginal ultrasound image showing the gestational sac with fetal pole within the uterus

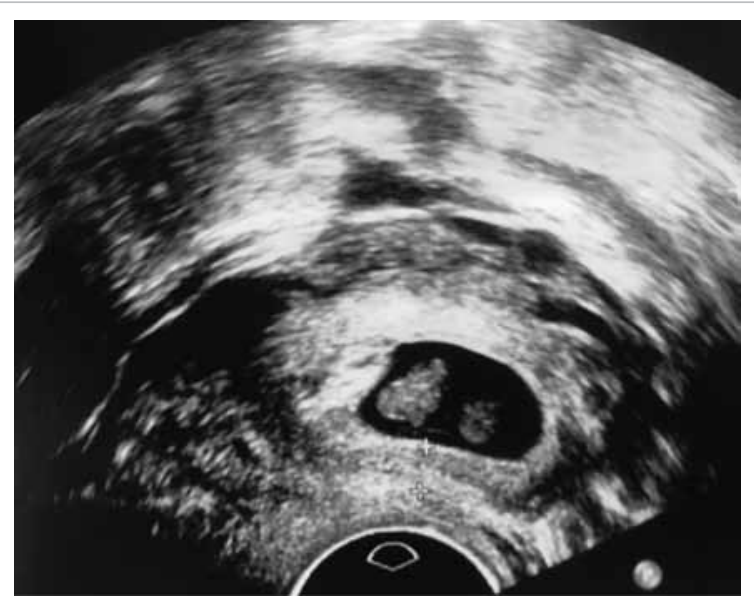

FIG 2. Transvaginal ultrasound image showing only minimal thickness of anterior myometrium adjacent to the gestational sac

implanted directly onto the scar.

Magnetic resonance imaging showed a $1.7-\mathrm{cm}$ defect at the anterior lower segment of the myometrium, corresponding to the Caesarean section scar. It was distended by a gestational sac. A singleton pregnancy was identified with crown-rump length consistent with gestational age. Trophoblastic tissue was seen implanted onto the serosa of the uterus (Fig 3). Overall MRI findings were compatible with Caesarean scar ectopic pregnancy. There was no 
direct extension of trophoblastic tissue into adjacent organs such as the urinary bladder or sign of uterine rupture (Fig 4).

The superior contrast resolution in MRI for different soft tissues is advantageous in the differentiation of uterine serosa, myometrium,

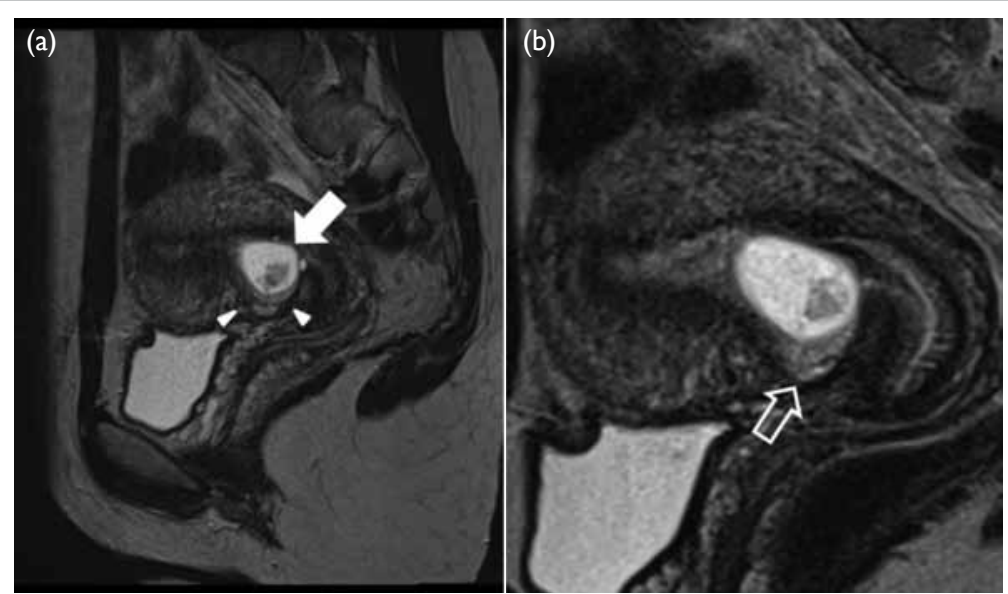

FIG 3. (a) Sagittal T2-weighted magnetic resonance imaging (MRI) showing a $T 2$ hyperintense structure at the inferior uterus, compatible with the gestational sac (white arrow) with fetal pole partially seen within. A defect at the anterior myometrium is seen at the lower anterior uterine wall, corresponding to Caesarean scar (white arrowheads) and is infiltrated by T2 hyperintense trophoblastic tissue. (b) Sagittal T2-weighted MRI showing a thin T2 hypointense layer that represents serosa (empty white arrow) covering the anterior aspect of the trophoblastic tissue. No evidence of uterine perforation is noted

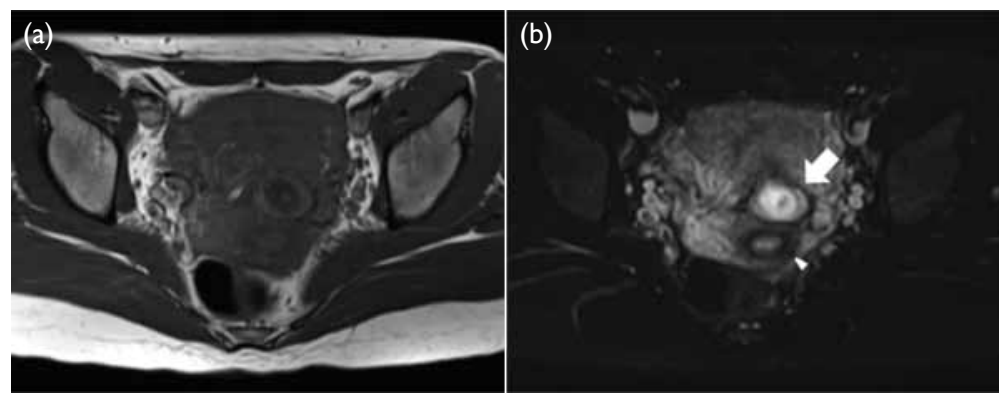

FIG 4. (a) Axial TI-weighted magnetic resonance imaging (MRI) of the pelvis showing no abnormal TI hyperintense fluid in the pouch of Douglas to suggest haemoperitoneum. (b) Axial T2-weighted fat-suppressed MRI of the pelvis showing no abnormal T2 hyperintense signal in the pouch of Douglas to suggest intraperitoneal free fluid.A T2 hyperintense structure is seen at the inferior aspect of the uterus, corresponding to the gestational sac (white arrow). The cervix (white arrowhead) is seen more posteriorly endometrium, and trophoblastic tissue. This helped confirm the diagnosis of Caesarean scar ectopic pregnancy in our patient and would have been difficult if only ultrasound findings were available.

The patient received intramuscular methotrexate therapy. Serial beta-human chorionic gonadotropin levels showed a decreasing trend. Subsequent definitive treatment with suction evacuation was performed. The patient made an uneventful recovery.

\section{Author contributions}

Concept and design of the study: All authors.

Acquisition of data: EMF Wong, W Shu.

Analysis and interpretation of data: EMF Wong, W Shu.

Drafting of the manuscript: JAWK Tang.

Critical revision for important intellectual content: JAWK

Tang, EMF Wong.

\section{Declaration}

All authors have disclosed no conflicts of interest. All authors had full access to the data, contributed to the study, approved the final version for publication, and take responsibility for its accuracy and integrity.

\footnotetext{
${ }^{1}$ JAWK Tang *, MB, ChB, FRCR

${ }^{1}$ EMF Wong, MB, BS, FHKAM (Radiology)

${ }^{2}$ W Shu, MB, BCh, FHKCOG
}

1 Department of Radiology

${ }^{2}$ Department of Obstetrics and Gynaecology

Pamela Youde Nethersole Eastern Hospital, Chai Wan, Hong Kong

* Corresponding author: tangwingkin2000@gmail.com

\section{References}

1. Seow KM, Huang LW, Lin YH, Lin MY, Tsai YL, Hwang JL. Caesarean scar pregnancy: issues in management. Ultrasound Obstet Gynecol 2004;23:247-53.

2. Jurkovic D, Hillaby K, Woelfer B, Lawrence A, Salim R, Elson CJ. First-trimester diagnosis and management of pregnancies implanted into the lower uterine segment caesarean section scar. Ultrasound Obstet Gynecol 2003;21:220-7.

3. Michaels AY, Washburn EE, Pocius KD, Benson CB, Doubilet PM, Carusi DA. Outcome of cesarean scar pregnancies diagnosed sonographically in the first trimester. J Ultrasound Med 2015;34:595-9.

4. Kao LY, Scheinfeld MH, Chernyak V, Rozenblit AM, Oh S, Dym RJ. Beyond ultrasound: CT and MRI of ectopic pregnancy. AJR Am J Roentgenol 2014;202:904-11.

5. Alalade AO, Smith FJ, Kendall CE, Odejinmi F. Evidencebased management of non-tubal ectopic pregnancies. J Obstet Gynaecol 2017;37:982-91. 